\title{
Mechanical Properties of Biocompatible Beta-Type Titanium Alloy Coated with Calcium Phosphate Invert Glass-Ceramic Layer
}

\author{
Toshikazu Akahori ${ }^{1}$, Mitsuo Niinomi ${ }^{1}$, Yoshihiko Koyanagi ${ }^{1}$, Toshihiro Kasuga ${ }^{2}$, \\ Hiroyuki Toda ${ }^{1}$, Hisao Fukui ${ }^{3}$ and Michiharu Ogawa ${ }^{4}$ \\ ${ }^{1}$ Department of Production Systems Engineering, Toyohashi University of Technology, Toyohashi 441-8580, Japan \\ ${ }^{2}$ Department of Materials Science and Engineering, Nagoya Institute of Technology, Nagoya 466-8555, Japan \\ ${ }^{3}$ School of Dentistry, Aichi-Gakuin University, Nagoya 464-8650, Japan \\ ${ }^{4} R \&$ D, Daido Steel Co., Ltd., Nagoya 457-8584, Japan
}

The presence of calcium phosphate invert glass-ceramic (designated as CPIG) layer on the surface of artificial implant products can improve the bonding between these products and bones. In this study, the morphology of the CPIG layer on the surface of a $\beta$-type titanium alloy, $\mathrm{Ti}-29 \mathrm{Nb}-13 \mathrm{Ta}-4.6 \mathrm{Zr}$ (TNTZ), was investigated for biomaterial applications by a dip-coating treatment. Furthermore, the mechanical properties of TNTZ coated with the CPIG layer were also investigated.

In the CPIG layer, a compositionally gradient zone with a thickness of approximately $2.0 \mu \mathrm{m}$ exists on the surface of the TNTZ. The titanium concentration in the zone increases with the decreasing distance from the CPIG surface toward the base materials. On the other hand, calcium and phosphorus concentrations in the zone increase with the distance from the TNTZ surface. The tensile bonding strength between TNTZ and the CPIG layer is $25 \mathrm{MPa}$ and that between aged TNTZ and the CPIG layer is $18.6 \mathrm{MPa}$.

For easily understanding the change in mechanical properties by a dip-coating treatment, the values of those on TNTZ and TNTZ coated with CPIG layer were shown as follows. The tensile strength increases remarkably by a dip-coating treatment as compared with that of assolutionized TNTZ while the elongation is a reverse trend. Young's modulus of TNTZ and aged TNTZ coated with the CPIG increases by 15 to $27 \mathrm{GPa}$ after the dip-coating treatment as compared with that of as-solutionized TNTZ (approximately $60 \mathrm{GPa}$ ). The fatigue limit of TNTZ coated with the CPIG layer is nearly equal to that (approximately $300 \mathrm{MPa}$ ) of as-solutionized TNTZ. On the other hand, the fatigue limit of aged TNTZ coated with the CPIG layer is a $100 \mathrm{MPa}$ higher than that of as-solutionized TNTZ.

(Received January 18, 2005; Accepted May 16, 2005; Published July 15, 2005)

Keywords: titanium-29 mass\%niobium-13 mass\%tantalum-4.6 mass\%zirconium, bioactive glass, microstructure, tensile properties, Young's modulus, fatigue properties

\section{Introduction}

Biocompatible Ti-29Nb-13Ta-4.6Zr (TNTZ) developed by the authors can be used in biomedical applications due to its good mechanical properties such as high specific strength and elongation. ${ }^{1-5)}$ TNTZ has a low Young's modulus of approximately $60 \mathrm{GPa}$, very low cyto-toxicty, similar to that of pure $\mathrm{Ti}$, and good biocompatibility with living tissues. ${ }^{6}$ However, it lacks bioactivity, which is the ability to directly form a chemical bond with bones although its biocompatibility is inadequate. A stem-a part of artificial joins-and dental implants made of metallic materials are required to strongly bond with living bone. However, they themselves cannot form a chemical bond with living bone.

The bioactive ceramic surface modification is effective in improving the biocompatibility of TNTZ. Calcium phosphate ceramics such as hydroxyapatite $\left(\mathrm{Ca}_{5}\left(\mathrm{PO}_{4}\right)_{3} \mathrm{OH} ; \mathrm{HA}\right)$ or $\beta$ tricalcium phosphate $\left(\beta-\mathrm{Ca}_{3}\left(\mathrm{PO}_{4}\right)_{2}\right.$; TCP) possess bioactivity. ${ }^{7,8)}$ Bioactivity is required in some portions of artificial substitutes for hard tissues. Many types of HA- and TCPcoating methods on titanium or titanium alloys have been reported so far. ${ }^{9-16)}$ Among them, the calcium invert glassceramic coating method, which is the dip-coating treatment, is simple and highly applicable to TNTZ. ${ }^{17,18)}$ This method includes heating at $1073 \mathrm{~K}$. Since firing is conducted above the beta transus temperature of TNTZ during-coating process, there is a possibility that the mechanical properties of TNTZ are degraded during firing. In such a case, heat treatments such as aging, etc., are needed to improve the mechanical properties of TNTZ after conducting the calcium invert glass-ceramic coating process. However, there is a possibility that the characteristics of the aged TNTZ coated with a calcium invert glass-ceramic layer might be degraded as compared with those of TNTZ that has undergone general aging after the solution treatment. Furthermore, there is a possibility that the coating layer will be exfoliated due to the difference in thermal expansion coefficients between the TNTZ matrix and the coating layer when the aging is conducted.

Therefore, the morphology of calcium phosphate invert glass-ceramic layer, and the mechanical properties of TNTZ and heat-treated TNTZ coated with this layer were investigated, where the change of mechanical properties in air are only done due to compare to TNTZ subjected to solution treatment (ST) and aging after ST although that in vitro is very important.

\section{Experimental Procedures}

The material used in this study was hot forged bars of Ti$29 \mathrm{Nb}-13 \mathrm{Ta}-4.6 \mathrm{Zr}$ (TNTZ), $11 \mathrm{~mm}$ in diameter.

Prior to the dip-coating of calcium phosphate invert glass, the solution treatment was conducted in vacuum on TNTZ bars at $1063 \mathrm{~K}$ - the temperature above the beta transus temperature of TNTZ (approximately 1013 K). As-solutionized TNTZ is termed as ST.

In this study, specimens with a diameter of $10 \mathrm{~mm}$ and thickness of $2.0 \mathrm{~mm}$ for the Vickers hardness tests were machined from ST. The surfaces of specimens of these specimens were subjected to polishing using a wet emery paper with a grid of \#600.

The bonding strength between the coated layer and the 
base material is measured using specimens with a diameter of $10 \mathrm{~mm}$ and a height of $20 \mathrm{~mm}$ machined from ST. To enhance the adhesion between the TNTZ matrix and coating layer, the surfaces of these specimens were subjected to sand-blasting, where the surface roughness achieved was approximately $1.29 \mu \mathrm{m}$ on the average, after polishing using a wet emery paper with a grid of \#600.

For the tensile and plain fatigue tests, round bar tensile specimens with a diameter of $10 \mathrm{~mm}$ and a gauge length of $20 \mathrm{~mm}$ were machined from ST. These specimens were then subjected to sand blasting after polishing using a wet emery paper with a grid of \#600. In particular, for the fatigue test, the specimens in the solutionized condition were buffpolished to get a mirror surface having a roughness of approximately $0.01 \mu \mathrm{m}$ on the average after polishing using a wet emery paper with a grid of \#1500.

For the measurement of Young's modulus, specimens with a diameter of $10 \mathrm{~mm}$ and a length of $70 \mathrm{~mm}$ were machined. These surfaces of specimens were subjected to sand blasting after polishing using a wet emery paper with a grid of $\# 600$.

Each specimen was dipped into the slurry of calcium phosphate invert glass powder $\left(60 \mathrm{CaO}-30 \mathrm{P}_{2} \mathrm{O}_{5}-7 \mathrm{Na}_{2} \mathrm{O}-\right.$ $3 \mathrm{TiO}$ ) and methanol and lifted at a speed of $1.4 \mathrm{~mm} / \mathrm{s}$. The dipped specimen was dried in air at room temperature for $1.8 \mathrm{ks}$. The thickness of calcium phosphate invert glassceramic (designated as CPIG) layer was contralled at approximately $5 \mu \mathrm{m}$ by the concentration of slurry. After the dip-coating of CPIG, the coated specimen was heated at $1073 \mathrm{~K}$ for $0.9 \mathrm{ks}$ followed by furnace cooling to room temperature. The coated specimen is termed as $\mathrm{DC}_{5}$. The dipcaoting treatment process carried out for TNTZ is schematically shown in Fig. 1.

Part of $\mathrm{DC}_{5}$ specimens were aged at $723 \mathrm{~K}$ for $259.2 \mathrm{ks}$ in vacuum followed by air-cooling in order to improve their mechanical properties. These specimens are termed as the aged $\mathrm{DC}_{5}$ and their aging process is also schematically shown in Fig. 1.

Microstructural observations of ST, $\mathrm{DC}_{5}$, and aged $\mathrm{DC}_{5}$ were carried out using a scanning electron microscopy (SEM) after buff polishing and etching.

The X-ray diffraction analysis was carried out using a $\mathrm{Cu}$ target with an accelerating voltage of $40 \mathrm{kV}$ and a current of $30 \mathrm{~mA}$.

The Vickers hardness was measured using a Vickers hardness tester with a load of $0.49 \mathrm{~N}$ and a holding time of $15 \mathrm{~s}$ after buff polishing the specimen.

The coating layer boundary and near the surface of the TNTZ matrix were observed using an SEM with an energy dispersive X-ray (EDX) after polishing the specimen and coated it with $\mathrm{Pt}$.
The aforementioned columnar specimens of $\mathrm{DC}_{5}$ and aged $\mathrm{DC}_{5}$ were used to evaluate the tensile bonding strength of the coating layers. A bonding agent for dental applications, (super bond orthomite), was applied to the surface of the coating layer of each specimen, and the surface was then bonded with a columnar stainless steel fixture whose size was identical to that of the columnar specimens of $\mathrm{DC}_{5}$ and aged $\mathrm{DC}_{5}$. Subsequently, the bonded specimens were dried in air at room temperature for $86.4 \mathrm{ks}$ and subjected to the tensile bonding test. The tests were conducted at a crosshead speed of $1.67 \times 10^{-5} \mathrm{~m} / \mathrm{s}$ in air at room temperature by using an Instron type tensile testing machine. The specimens were carefully set up the chucking jig not to occur some shear stresses at the boundary between TNTZ and the fixture. The tensile bonding strength test system was schematically shown in Fig. 2.

The tensile test of each specimen was conducted using an Instron type machine at a crosshead speed of $8.33 \times 10^{-6}$ $\mathrm{m} / \mathrm{s}$ in air at room temperature. A load cell of the machine detected the load and the strain was detected by a strain gauge attached to the gauge part of the specimen.

The fatigue tests were conduted on the plain fatigue test specimens using an electro-servo-hydraulic machine. The test was conducted at a frequency of $10 \mathrm{~Hz}$ with a stress ratio, $R=0.1$, in air at $295 \mathrm{~K}$. The maximum cyclic stress, at which the specimen was not failure at $10^{7}$ cycles, was defined as the plain fatigue limit in this study.

The fracture surface observation was carried out using an SEM.

The Young's modulus of each specimen was measured in air at room temperature using a resonance method. This method is based on the measurement of the fundamental resonant frequencies of the material during vibration.

\section{Results and Discussion}

\subsection{Microstructure and age hardening characteristics}

The microstructures of $\mathrm{ST}, \mathrm{DC}_{5}$ aged $\mathrm{DC}_{5}$ were comprised

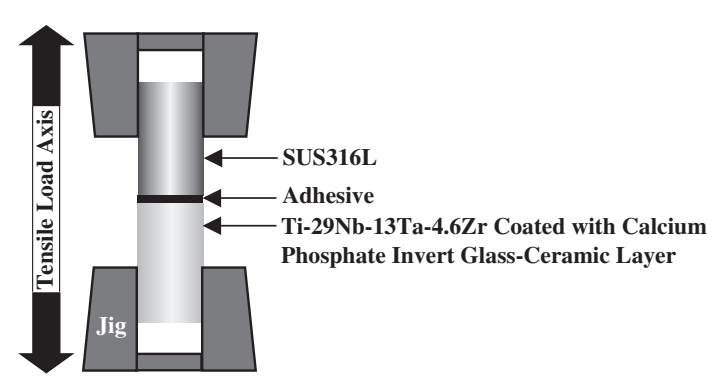

Fig. 2 Schematic drawing of tensile bonding strength testing system.
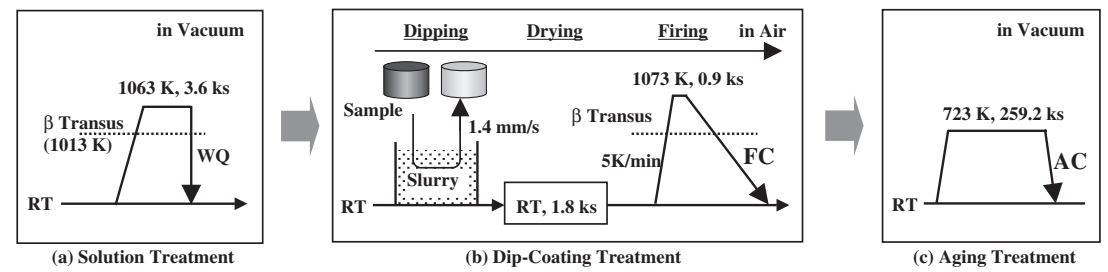

Fig. 1 Schematic drawings of (a) solution treatment, (b) dip-coating treatment and (c) aging treatment. RT, WQ, FC and AC indicate room temperature, water quenching, furnace cooling and air cooling, respectively. 


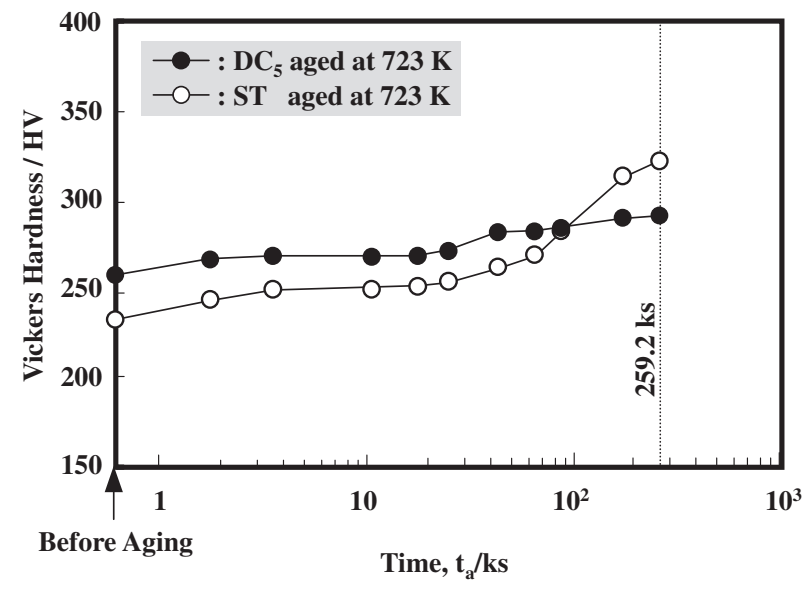

Fig. 3 Aging curves of Ti-29Nb-13Ta-4.6Zr, TNTZ, conducted with solution treatment, ST, and TNTZ coated with calcium phosphate invert glass-ceramic, CPIG, layer, $\mathrm{DC}_{5}$.

of $\beta$ phase grains of a diameter of approximately $20 \mu \mathrm{m}$. Alpha and omega phase, which is expected to exist, are not observed by SEM observation probably due to the super fine precipitation.

Figure 3 shows the age hardening curves of $\mathrm{ST}_{\mathrm{T}}$ and $\mathrm{DC}_{5}$ specimens. The Vickers hardness of $\mathrm{DC}_{5}$ before aging is higher than that of ST due to the $\omega$ phase precipitation during furnace cooling after the firing. The Vickers hardness of $\mathrm{DC}_{5}$ gradually increases up to $259.2 \mathrm{ks}$. The Vickers hardness of $\mathrm{DC}_{5}$ at an aging time of $86.4 \mathrm{ks}$ is nearly equal to that of ST. The rate of increase in the hardness of $\mathrm{DC}_{5}$ is nearly equal to that of ST up to an aging time of $43.2 \mathrm{ks}$. For the aging time from 43.2 to $259.2 \mathrm{ks}$, the rate of increase in Vickers hardness of ST is higher than that of $\mathrm{DC}_{5}$. The average Vickers hardness of $\mathrm{DC}_{5}$ and ST for an aging time of $259.2 \mathrm{ks}$ is 241 and $270 \mathrm{HV}$, respectively. It has been reported that Vickers hardness at the peak of aging of cold-rolled TNTZ subjected to aging at $723 \mathrm{~K}$ is over $3.0 \mathrm{Ms} .{ }^{19)}$ Therefore, the aging time selected in this study is in under-aging conditions.

Figure 4 shows the change of Vickers hardness of $\mathrm{DC}_{5}$ specimens at the different position in the specimen thickness measured of various aging time. The Vickers hardness for the aging time range of 18.0 to $86.4 \mathrm{ks}$ increases in keeping with the hardness gradient near the surface of the specimen because the oxide layer and the $\alpha$ case exist near the surface of specimen when heating is carried out in air. The Vickers hardness of near the surface of the specimen for aging of $259.2 \mathrm{ks}$ is the greatest with a value of $376 \mathrm{HV}$.

\subsection{Morphology of coating layer}

Figure 5 shows SEM micrographs of specimen surfaces and cross sections of $\mathrm{DC}_{5}$ and aged $\mathrm{DC}_{5}$. The CPIG layers of $\mathrm{DC}_{5}$ and aged $\mathrm{DC}_{5}$ show microstructures with a large number of pores, few micrometers in diameter and approximately $5.0 \mu \mathrm{m}$ in thickness. There are no cracks at the boundary between the CPIG layer and each TNTZ and no exfoliations on the CPIG layer on $\mathrm{DC}_{5}$ and aged $\mathrm{DC}_{5}$ although the thermal expansion coefficients of titanium and TCP range from $8 \times 10^{-6}$ to $10 \times 10^{-6} \mathrm{deg}^{-1}$ and $11 \times 10^{-6}$ to $15 \times$ $10^{-6} \mathrm{deg}^{-1}$, respectively. ${ }^{18)}$ A number of cracks and exfoliations were observed on the surface of TNTZ coated with

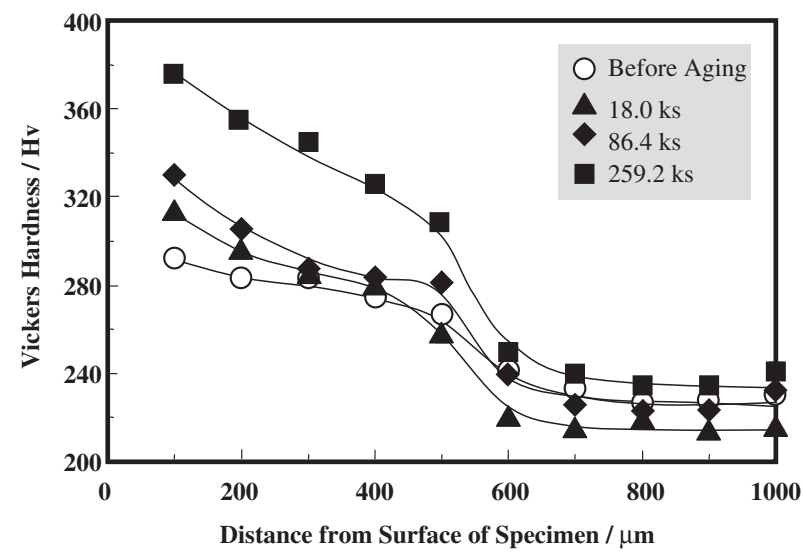

Fig. 4 Change in Vickers hardness of $\mathrm{DC}_{5}$ at various aging time as a function of distance from surface.
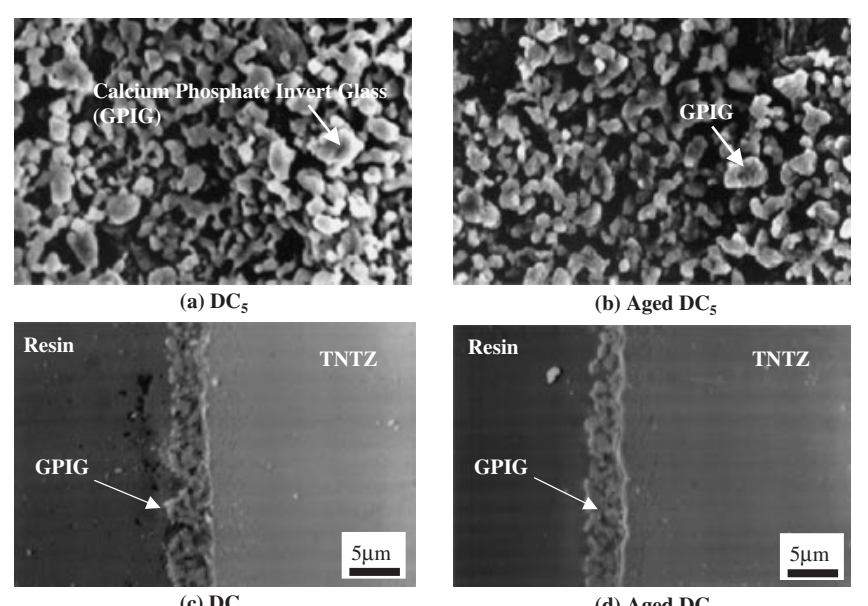

(d) Aged $\mathrm{DC}_{5}$

Fig. 5 SEM micrographs of morphologies of (a) $\mathrm{DC}_{5}$, and (b) aged $\mathrm{DC}_{5}$, and cross section of near CPIG layer of (c) $\mathrm{DC}_{5}$ and (d) aged $\mathrm{DC}_{5}$.

CPIG layer with a thickness of $15 \mu \mathrm{m}$ after heating. ${ }^{20)}$ It is considered that the CPIG layer with a thickness of $5 \mu \mathrm{m}$ composed of the compositional gradient zone $(3 \mu \mathrm{m})$ is optimum size.

Figure 6 shows an SEM micrograph of the cross section of $\mathrm{DC}_{5}$ and results of the line analysis of elements measured by EDX along the indicated line. The composition of elements shows gradient within the thickness of the layer, thus forming the compositional gradient zone. The titanium concentration in the zone increases with the decreasing distance from the CPIG surface toward the base materials. On the other hand, calcium and phosphorus concentrations in the zone increase with the distance from the TNTZ surface. And the matrix, almost devoid of no calcium, comes in contact with the surface.

The X-ray diffraction profiles of the surfaces of $\mathrm{DC}_{5}$ and aged $\mathrm{DC}_{5}$ show the phases of $\beta$-TPC, $\beta$-CPP, $\beta, \alpha$, and $\mathrm{TiO}_{2}$, as shown in Fig. 7. As indicated by the results of the X-ray profile, it is considered that the coating layers comprise of a large amount of $\beta$-TCP and a small amount of $\beta$-CPP. The peak strength of $\mathrm{TiO}_{2}$ is clearly observed as compared with TNTZ subjected to solution treatment in vacuum ${ }^{19)}$ because TNTZ is conducted with a heating in air.

Figure 8 shows the X-ray diffraction profiles, measured at 


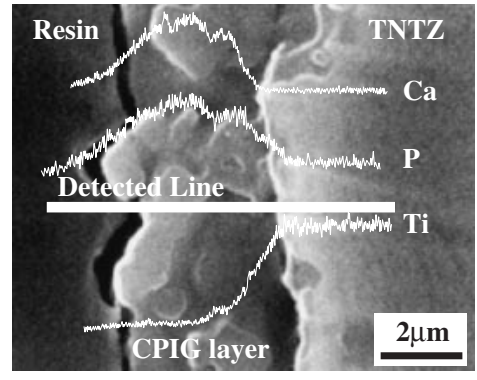

Fig. 6 SEM micrograph of cross section of $\mathrm{DC}_{5}$, and $\mathrm{Ti}, \mathrm{P}$ and $\mathrm{Ca}$ concentration profiles along detected line.

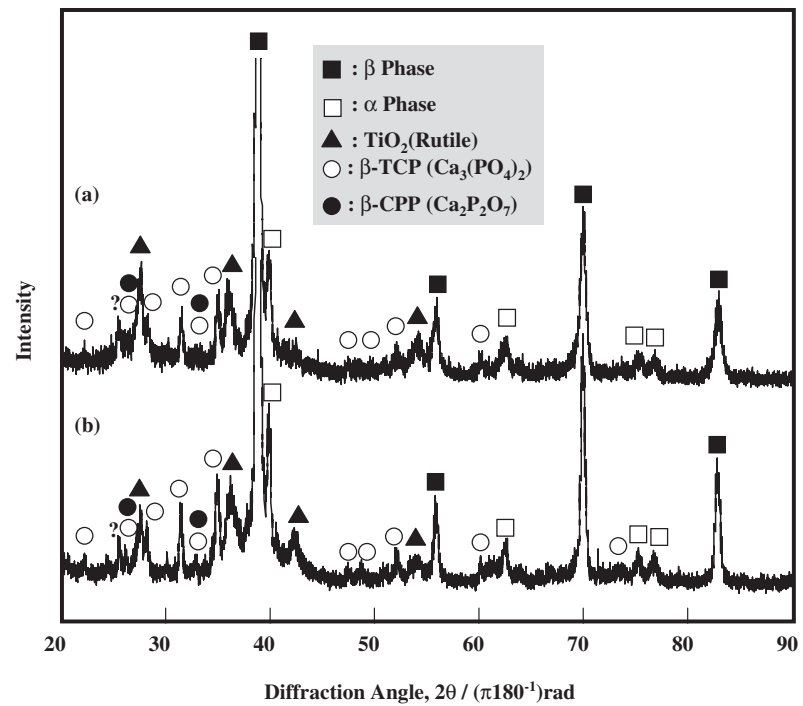

Fig. 7 X-ray diffraction profiles of surfaces of (a) $\mathrm{DC}_{5}$ and (b) aged $\mathrm{DC}_{5}$.

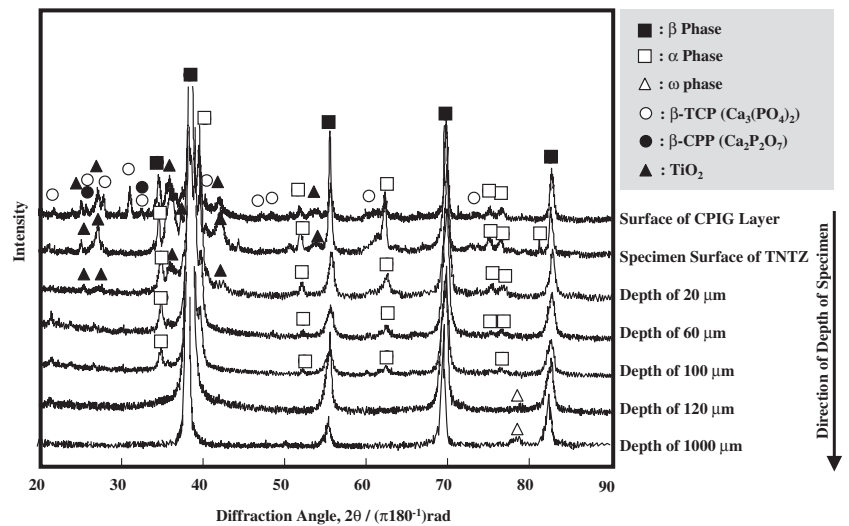

Fig. 8 X-ray diffraction profiles of $\mathrm{DC}_{5}$ as a function of distance from surface of specimen.

the different depth from surface of $\mathrm{DC}_{5}$ specimen, the CPIG layer. The surface is removed from the specimen surface. The oxide layer $\left(\mathrm{TiO}_{2}\right)$ is observed up to $20 \mu \mathrm{m}$ from the boundary between the CPIG layer and the TNTZ matrix. Subsequently, the oxygen-rich region, which is considered to be an $\alpha$ case, and consists of the $\alpha$ phase, exists up to approximately $100 \mu \mathrm{m}$ from the boundary. The same phenomenon is also observed in aged $\mathrm{DC}_{5}$.

No $\omega$ phase was detected up to a depth of approximately $200 \mu \mathrm{m}$ from the specimen surface of aged $\mathrm{DC}_{5}$. A peak of $\omega$ phase was detected at approximately the same distance from

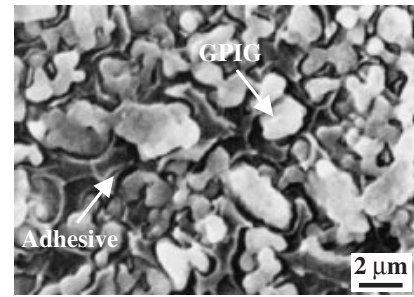

(a) $\mathrm{DC}_{5}$

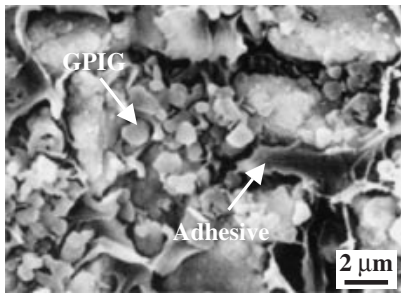

(b) Aged $\mathrm{DC}_{5}$
Fig. 9 SEM fractographs of (a) $\mathrm{DC}_{5}$ and (b) aged $\mathrm{DC}_{5}$ after tensile bonding strength tests.

the specimen surface of $\mathrm{DC}_{5}$. As mentioned earlier, $\omega$ phase is considered to precipitate during the firing treatment.

\subsection{Tensile bonding strength of coating layer}

The tensile bonding strengths between the base material and the CPIG layer of $\mathrm{DC}_{5}$ and aged $\mathrm{DC}_{5}$ were approximately 25.0 and $18.6 \mathrm{MPa}$, respectively. The tensile bonding strengths of $\mathrm{DC}_{5}$ and aged $\mathrm{DC}_{5}$ are much greater than that of pure titanium and its alloys, whose tensile boding strength is in the range of 4.15-13.9 MPa and on which the HA powders and AW glass layer were mechanically coated. ${ }^{21,22)}$ Therefore, applied to pure titanium and its alloys, this coating method is expected to acquire relatively high tensile bonding strength.

All specimen surfaces of $\mathrm{DC}_{5}$ and aged $\mathrm{DC}_{5}$ from tensile bonding tests are observed fractured CPIG and a portion of an adhesive (super bond orthomite), where the zone of TNTZ is not observed, as shown in Fig. 9. In other words, the coating layer is strongly adhered to the TNTZ matrix due to the presence of the compositionally gradient zone within the CPIG layer and the wedge effect of the TNTZ surface by shot blasting. Therefore, it is difficult to investigate the true tensile bonding strength due to very high interface bonding between the TNTZ and the CPIG layer.

\subsection{Tensile properties}

The tensile strength, $0.2-\%$ proof stress and elongation of $\mathrm{ST}, \mathrm{DC}_{5}$, and aged $\mathrm{DC}_{5}$ are shown in Fig. 10. The values of tensile properties of $\mathrm{ST}, \mathrm{DC}_{5}$, and aged $\mathrm{DC}_{5}$ are shown as follows for easily understanding the change in those by a dipcoating process or compare with those of the others metallic

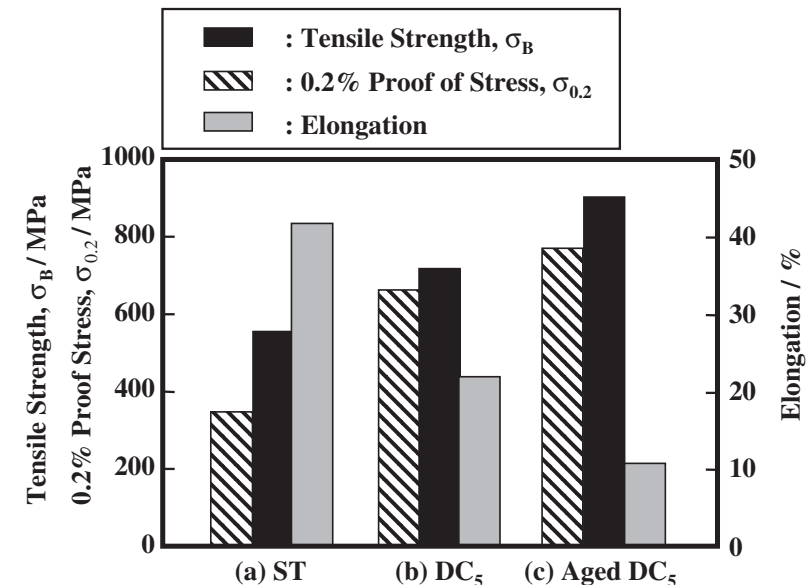

Fig. 10 Tensile properties of (a) ST, (b) $\mathrm{DC}_{5}$ and (c) aged $\mathrm{DC}_{5}$. 


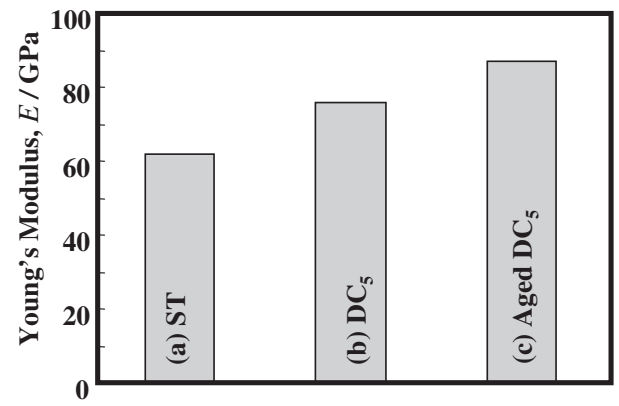

Fig. 11 Young's moduli of (a) ST, (b) $\mathrm{DC}_{5}$ and (c) aged $\mathrm{DC}_{5}$.

materials for biomedical applications. The tensile strength of $\mathrm{ST}$ is $549 \mathrm{MPa}$, and is minimum. However, its elongation is $41.6 \%$ and is the highest. The tensile strengths of $\mathrm{DC}_{5}$ and aged $\mathrm{DC}_{5}$ are $713 \mathrm{MPa}$ and $897 \mathrm{MPa}$, respectively. The tensile strength of aged $\mathrm{DC}_{5}$ is greater than that of ST by $300 \mathrm{MPa}$. However, the elongations of $\mathrm{DC}_{5}$ and aged $\mathrm{DC}_{5}$ are $21.7 \%$ and $10.5 \%$, respectively; these values are half and one-fourth of that of ST, respectively.

The increase of strength of $\mathrm{DC}_{5}$ can be mainly contributed to the age hardening by the precipitation of $\omega$ phase during cooling in air.

The tensile strength of aged $\mathrm{DC}_{5}$ is pretty high, but its elongation shows a reverse trend. This inverse relationship between the tensile strength and elongation may become evident with on increasing the volume fraction of the fine $\alpha$ phase that relatively enhances the brittleness of the matrix.

\subsection{Young's modulus}

The Young's moduli of ST, $\mathrm{DC}_{5}$ and aged $\mathrm{DC}_{5}$ are shown in Fig. 11. The Young's moduli of $\mathrm{ST}$ and $\mathrm{DC}_{5}$ are approximately 60 and $75 \mathrm{GPa}$, respectively. Therefore, Young's modulus of TNTZ increases by approximately $15 \mathrm{GPa}$ after the dip-coating treatment. This increase in Young's modulus is due to the precipitation of the $\omega$ phase during firing and subsequent cooling. The Young's modulus of aged $\mathrm{DC}_{5}$ increases further and has a value of approximately $87 \mathrm{MPa}$. The Young's modulus of TNTZ subjected to aging treatment at $723 \mathrm{~K}$ for $259.2 \mathrm{ks}$ after the solution treatment at $1063 \mathrm{~K}$ for $3.6 \mathrm{ks}$ was approximately $88 \mathrm{GPa}^{23}$ )

\subsection{Fatigue properties}

Figure 12 shows the relationship between maximum cyclic stress and number of cycles to failure of $\mathrm{ST}, \mathrm{DC}_{5}$, and aged $\mathrm{DC}_{5}$. The fatigue strength of $\mathrm{DC}_{5}$ is similar to that of ST in low cycle fatigue life $\left(<10^{5}\right.$ cycles $)$ and high cycle fatigue life ( $>10^{5}$ cycles) regions. The fatigue limits of ST, $\mathrm{DC}_{5}$ are $330 \mathrm{MPa}$ and $325 \mathrm{MPa}$, respectively. However, the fatigue ratio ( $f$; fatigue limit/tensile strength) of $\mathrm{DC}_{5}$ is 0.46 , and this value is smaller than that of ST (0.60). In general, the fatigue strength increases proportionally with increasing tensile strength and $0.2 \%$ proof stress. The tensile strength and $0.2 \%$ proof stress of $\mathrm{DC}_{5}$ are much greater than those of ST. This is attributed to the difference in the surface roughness between $\mathrm{DC}_{5}$ and $\mathrm{ST}$. The surface of $\mathrm{DC}_{5}$, subjected to sand-blasting before the dip-coating treatment, is considerably rough as compared with that of the buffpolished ST. In general, the fatigue strength of titanium and

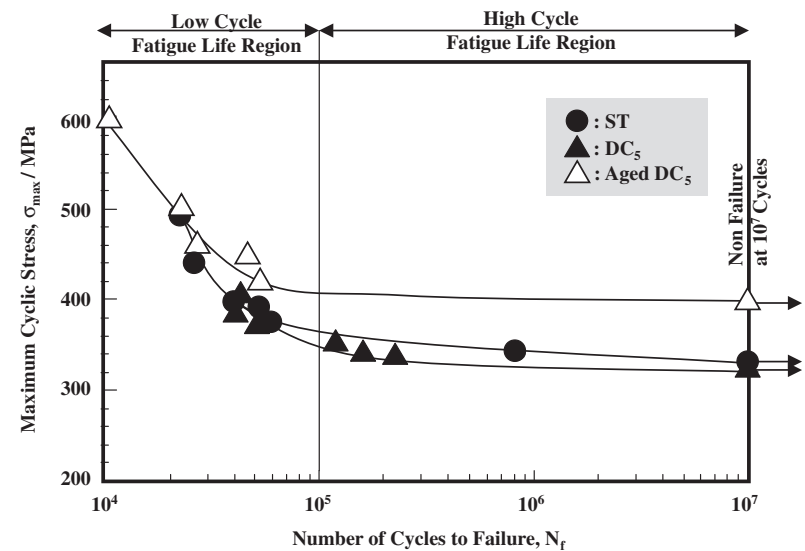

Fig. 12 S-N curves of (a) ST, (b) $\mathrm{DC}_{5}$ and (c) aged $\mathrm{DC}_{5}$.

its alloys, which have high notch sensitivity, deteriorate remarkably with increasing surface roughness. ${ }^{24,25)}$ The fatigue crack initiation lives of typical titanium alloys such as $\mathrm{Ti}-6 \mathrm{Al}-7 \mathrm{Nb}$ and $\mathrm{Ti}-6 \mathrm{Al}-4 \mathrm{~V}$ ELI, used in biomedical applications, have $50 \%$ or more of their total fatigue life. ${ }^{26)}$ Hence, due to the decrease in the fatigue crack initiation life of $\mathrm{DC}_{5}$, its total fatigue life also decreases significantly.

In particular, the fatigue strength of aged $\mathrm{DC}_{5}$ in the high cycle fatigue life region is much greater than that of $\mathrm{DC}_{5}$. Its fatigue limit and $f$ are $400 \mathrm{MPa}$ and 0.46 , respectively. The fatigue limit of cold-rolled TNTZ subjected to aging at $723 \mathrm{~K}$ for $259.2 \mathrm{ks}$ after the solution treatment is $680 \mathrm{MPa},{ }^{23}$ ) whereas that of aged $\mathrm{DC}_{5}$ is decreased by $280 \mathrm{MPa}$, where the values of fatigue limits are shown for easily understanding the change in those by a dip-coating process.

All fatigue cracks of $\mathrm{DC}_{5}$ and aged $\mathrm{DC}_{5}$ initiate at the very edge of the fatigue specimen surface composed of $\mathrm{TiO}_{2}$ and $\alpha$ case as shown in Fig. 13. While, that of ST was initiated at $\beta$ phases. Striations were formed at the stable crack propagation area of all types of material studied.

Figure 14 shows the SEM micrograph of the specimen surface of $\mathrm{DC}_{5}$ obtained from the fatigue test. The exfoliation of the CPIG layer is not observed on the surface. However, there are a number of micro-cracks in the CPIG layer because of a large difference in the Young's modulus between TNTZ and CPIG layer. Similar surface were observed in aged $\mathrm{DC}_{5}$ specimen.

It needs to investigate the fatigue properties in vitro in detail to acquire the credibility for practical applications.

\section{Conclusions}

The morphology of the calcium phosphate invert glassceramic (designated as CPIG) layer on the surface of $\beta$-type titanium alloy, $\mathrm{Ti}-29 \mathrm{Nb}-13 \mathrm{Ta}-4.6 \mathrm{Zr}$ (designated as TNTZ) was investigated for biomaterial applications by the dipcoating treatment. Furthermore, the mechanical properties of TNTZ coated with the coating layer were also investigated. The following results were obtained.

(1) There exists a compositionally gradient zone within the CPIG layer with a thickness of approximately $2.0 \mu \mathrm{m}$ on the surface of the TNTZ. The tensile bonding strength between TNTZ and the CPGI layer is $25 \mathrm{MPa}$ and that 


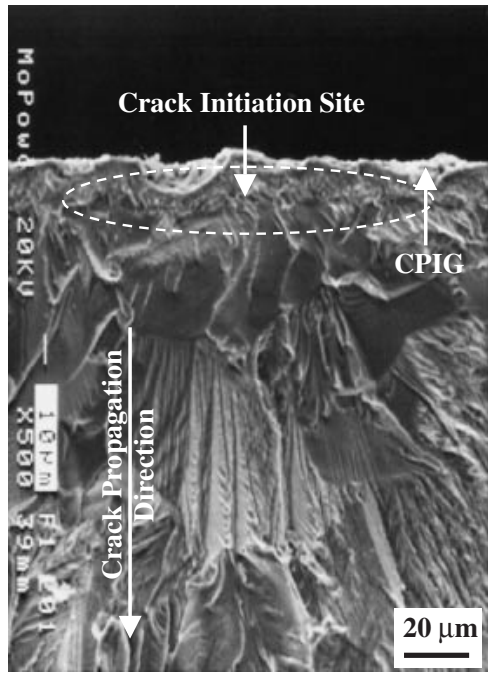

Fig. 13 SEM fractograph of $\mathrm{DC}_{5}$ in low cycle fatigue life region.

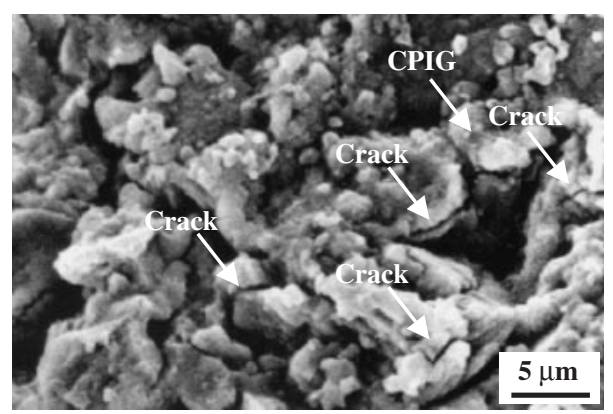

Fig. 14 SEM micrographs of specimen surface of $\mathrm{DC}_{5}$ after fatigue test.

between the aged TNTZ and the CPIG layer is $18.6 \mathrm{MPa}$, respectively.

(2) The tensile strengths of TNTZ and aged TNTZ coated with CPIG layer are 713 and $897 \mathrm{MPa}$, respectively. On the other hand, their elongations are 21.7 and $10.5 \%$, respectively, which are a half to quarter smaller than that of as-solutionized TNTZ.

(3) Young's moduli of TNTZ and aged TNTZ coated with the CPIG layer are approximately 75 and $87 \mathrm{GPa}$, respectively. Therefore, Young's modulus of TNTZ increases by approximately $15 \mathrm{GPa}$ by the dip-coating treatment process as compared with that of as-solutionized TNTZ.

(4) The fatigue limit of TNTZ coated with the CPIG layer is nearly equal to that of as-solutionized TNTZ subjected to solution treatment, while the fatigue limit of aged TNTZ coated with the CPIG layer is approximately $80 \mathrm{MPa}$ greater than that of as-solutionized TNTZ.

(5) TNTZ and aged TNTZ subjected to dip-coating treatment process exhibit sufficiently good mechanical properties such as tensile properties and a small Young's modulus for biomaterials except for relatively low fatigue strength. The mechanical properties of TNTZ subjected to the dip-coating treatment process are expected to sufficiently improve with aging conditions.

\section{Acknowledgments}

Certain parts of this study are supported by NED (New Energy and Industrial Technology Development Organization, Tokyo, Japan), Grant-in-Aid for Promoting Scientific Frontier Research from Ministry Education, Science and Culture (Tokyo, Japan), Grant-in-Aid for Scientific Research from Japan Society for Promotion of Science (Tokyo, Japan), the Mitsubishi Foundation (Tokyo, Japan), The Iron and Steel Institute of Japan (Tokyo, Japan), The Light Metal Education Foundation (Osaka, Japan), The Suzuki Foundation (Hamamatsu, Japan) and The Grant for the Excellent Research Project of Research Center for Future Technology, Toyohashi University of Technology.

\section{REFERENCES}

1) D. Kuroda, M. Niinomi, M. Morinaga, Y. Kato and T. Yashiro: Mater. Sci. Eng. A A243 (1998) 244-249.

2) M. Niinomi, D. Kuroda, K. Fukunaga, M. Morinaga, Y. Kato, T. Yashiro and A. Suzuki: Mater. Sci. Eng. A A263 (1999) 193-199.

3) M. Ikeda, S. Komatsu, I. Sowa and M. Niinomi: Met. Mater. Trans. A 33A (2002) 487-493.

4) D. Kuroda, M. Niinomi, T. Akahori, H. Fukui, A. Suzuki and J. Hasegawa: Structural Biomaterials for the 21st Century, Ed. by M. Niinomi, T. Okabe, E. H. Tallef, D. R. Lesure and H. E. Lippard, (TMS, 2001) pp. 99-106.

5) M. Niinomi, T. Hattori and S. Niwa: Biomaterials in Orthopedics, Ed. by M. J. Yaszemski, D. J. Trantolo, K. U. Lewandrowski, V. Hasirci, D. E. Altobelli and D. L. Wise, (Marcel Dekker, INC, 2004) pp. 41-62.

6) M. Niinomi, T. Hattori, K. Morikawa, T. Kasuga, A. Suzuki, H. Fukui and S. Niwa: Mater. Trans. 43 (2002) 2970-2977.

7) L. L. Hench: Bioceramics 74 (1991) 1487-1510.

8) R. H. Doremus: Bioceramics 27 (1992) 285-297.

9) W. R. Lancefield: An Introduction to Bioceramics, Ed. by L. L. Hench and J. Wilson, (1993) pp. 223-238.

10) Y. Fan, K. Duan and R. Wang: Biomaterials 26 (2005) 1623-1632.

11) T. Nonami, K. Naganuma and T. Kameyama: Mater. Jpn. 37 (1998) $856-858$.

12) S. Ding, T. Huang and C. Kao: Surf. Coating Tech. 165 (2003) 248257.

13) H. Kim, F. Miyaji, T. Kokubo and T. Nakamura: J. Cera. Soc. JPN 105 (1997) 111-116

14) T. Hanawa, M. Kon, H. Ukai, K. Murakami, Y. Miyamoto and K. Asaoka: J. Biomedical Mater. Res. 34 (1997) 273-278.

15) V. Nelea, C. Morosanu, M. Iliescu and I. N. Mihailescu: Surf. Coating Tech. 173 (2003) 315-322.

16) F. Liang, L. Zhou and K. Wang: Surf. Coating Tech. 165 (2003) 133139.

17) T. Kasauga, T. Mizuno, M. Watanabe, M. Nogami and M. Niinomi: Biomaterials 22 (2001) 577-582.

18) T. Kasuga: Mater. Jpn. 39 (2000) 250-255.

19) T. Akahori, M. Niinomi, K. Ishimizu, H. Fukui and A. Suzuki: J. Japan Inst. Metals 67 (2003) 652-660.

20) M. Niinomi, T. Akahori, T. Yamaguchi, T. Kasuga, H. Fukui and A. Suzuki: J. Inst. Met. 67 (2003) 604-613.

21) X. Zheng, M. Huang and C. Ding: Biomaterials 21 (2000) 841-849.

22) Y. C. Tsui, C. Doyle and T. W. Clyne: Biomaterials 19 (1998) 20152029.

23) T. Akahori, M. Niinomi, H. Fukui and A. Suzuki: Mater. Trans. 45 (2004) 1540-1548.

24) K. Hayashi, S. Nisida and N. Hattori: J. Jpn. Sci. Mechan. Eng. A 65 (1999) 2080-2085.

25) K. Minakawa: Tetsu-to-Hagané 75 (1989) 1104-1111.

26) T. Akahori, M. Niinomi, K. Fukunaga and I. Inagaki: Mater. Trans. A. 31A (2000) 1949-1958. 